\title{
In vitro and in vivo anti-angiogenic activity of girinimbine isolated from Murraya koenigii
}

This article was published in the following Dove Press journal:

Drug Design, Development and Therapy

3 March 2015

Number of times this article has been viewed

\section{Venoos Iman' \\ Hamed Karimian' \\ Syam Mohan ${ }^{2}$ \\ Yahya Hasan Hobani \\ Mohamed Ibrahim Noordin' \\ Mohd Rais Mustafa ${ }^{3}$ \\ Suzita Mohd Noor ${ }^{4}$ \\ 'Department of Pharmacy, Faculty of Medicine, University of Malaya, Kuala Lumpur, Malaysia; ${ }^{2}$ Medical Research \\ Center, University of Jazan, Jazan, Saudi Arabia; ${ }^{3}$ Department of Pharmacology, Centre for Natural Products and Drug Discovery (CENAR), Faculty of Medicine, University of Malaya, Kuala Lumpur, Malaysia; ${ }^{4}$ Department of Biomedical Science, Faculty of Medicine, University of Malaya, Kuala Lumpur, Malaysia}

Correspondence: Suzita Mohd Noor Department of Biomedical Science, Faculty of Medicine, University of Malaya, 50603 Kuala Lumpur, Malaysia

Tel +60 37967490 I

Fax +60 379676600

Email suzita@um.edu.my

\begin{abstract}
Girinimbine is a carbazole alkaloid isolated from the stem bark and root of Murraya koenigii. Here we report that girinimbine is an inhibitor of angiogenic activity both in vitro and in vivo. MTT results showed that girinimbine inhibited proliferation of human umbilical vein endothelial cells, while results from endothelial cell invasion, migration, tube formation, and wound healing assays demonstrated significant time- and dose-dependent inhibition by girinimbine. A proteome profiler array done on girinimbine-treated human umbilical vein endothelial cells showed that girinimbine had mediated regulation of pro-angiogenic and antiangiogenic proteins. The anti-angiogenic potential of girinimbine was also evidenced in vivo in the zebrafish embryo model wherein girinimbine inhibited neo vessel formation in zebrafish embryos following 24 hours of exposure. Together, these results showed that girinimbine could effectively suppress angiogenesis, suggestive of its therapeutic potential as a novel angiogenesis inhibitor.
\end{abstract}

Keywords: angiogenesis, inhibitor, carbazole alkaloid, zebrafish

\section{Introduction}

Angiogenesis has a critical role in tumor progression. Angiogenesis is a complex process which is defined as the development of new blood vessels from pre-existing vasculature, ${ }^{1}$ mainly involving endothelial cell proliferation, organization, and migration. ${ }^{2}$ Abnormal angiogenesis is associated with various pathological conditions such as cancer, rheumatoid arthritis, and diabetic retinopathy. ${ }^{3}$ In cancer states, a tumor remains dormant until it is capable of stimulating blood vessel growth from nearby capillaries as a prelude to metastasis and cancer progression. ${ }^{4}$ Therefore angiogenesis inhibition is considered an encouraging strategy in cancer therapy and other related diseases. ${ }^{5}$ In 2004 the US Food and Drug Administration (FDA) approved the first angiogenesis inhibitor bevacizumab $\left(\right.$ Avastin $\left.^{\circledR}\right)$ for the treatment of metastatic colorectal cancer. However, as of 2010, there were no more than ten drugs for this purpose approved by the US FDA. ${ }^{6}$

Murraya koenigii (curry tree) is an edible herb which is also used in folk medicine. It belongs to the Citrus family, Rutaceae, native to most parts of Asia including Malaysia, India, the People's Republic of China, and Sri Lanka. M. koenigii is a tonic plant and is used in various disease conditions, ${ }^{7}$ with a potential role as a remedy for cancer. ${ }^{8}$ Other uses, such as antioxidant properties, anti-fungal, anti-diabetic, anti-bacterial, anti-diarrheal and anti-dysentery effects have also been described. ${ }^{9}$ In addition, a mixture of $M$. koenigii leaves with fat separated butter is widely used for the treatment of diabetes, amebiasis, and hepatitis. ${ }^{10}$

Studies have established the anti-cancer potential of carbazole alkaloids against various cancer cell lines with some already entering clinical trials. ${ }^{11,12}$ In 1999 , 
Ramsewak et al reported that carbazole alkaloids obtained from $M$. koenigii showed cytotoxic capacity. ${ }^{13}$ Girinimbine was the first of many $M$. koenigii carbazole alkaloids that have since been isolated and identified. ${ }^{14}$ Girinimbine (3,3,5-trimethyl-11H-pyrano[3,2-a]carbazole, Figure 1A) is a pyranocarbazole isolated from the stem bark of M. koenigii, and is also present in Clausena heptaphylla and Clausena dunniana from the Rutaceae family. ${ }^{15,16}$ Girinimbine isolated from the root of $M$. koenigii was shown to have anticancer effects involving free radical scavenging and apoptosis. ${ }^{17,18}$ Furthermore it demonstrated anti-platelet activity through inhibition of cyclooxygenase activity. ${ }^{19}$ Girinimbine was also reported to be cytotoxic against various cell lines, causing cell death via apoptotic processes. Other pharmacological effects of pyranocarbazole girinimbine include anti-trichomonal, anti-bacterial, and anti-tumor activities. ${ }^{20-22}$

The zebrafish (Danio rerio) is a tropical freshwater fish capable of producing hundreds of embryos per mating under optimal conditions. These large numbers, optical clarity during embryonic development, short generation time, ease of maintenance, high permeability to small molecules, and ease of scoring blood vessel formation make the zebrafish embryo an attractive system for the study of genetics, immunity, cancer, and angiogenesis. ${ }^{23}$ Moreover, the formation of inter-segmental vessels (ISVs) and sub-intestinal veins in the early embryo is well characterized and easy to monitor for angiogenesis studies. ${ }^{24}$

Here, we demonstrated that girinimbine acts as antiangiogenic agent by dose- and time-dependent inhibition of angiogenesis in human umbilical vein endothelial cells (HUVECs) and zebrafish embryos. Our findings strongly suggest that girinimbine might be a potent agent for cancer therapeutics.

\section{Materials and methods Ethics statement}

All animal experimental procedures were approved by the Faculty of Medicine Institutional Animal Care and Use Committee (ethics number: 2013-11-12/PHARM/R/VI).

\section{Plant material}

Girinimbine used in this research was kindly gifted to us by Prof Mohamed Aspollah Sukari, Department of Chemistry, Faculty of Science, University Putra Malaysia. Extraction method and spectroscopic data have been reported previously. ${ }^{25}$ Stock solution of girinimbine was stored at a concentration of $10 \mathrm{mg} / \mathrm{mL}$ in dimethyl sulfoxide (DMSO). The final concentration of DMSO was $0.1 \%(\mathrm{v} / \mathrm{v})$. Different concentrations of girinimbine were prepared by serial dilution. DMSO (0.1\%) was used as control.

\section{Cell culture}

HUVECs, (Lonza, Basel, Switzerland) were cultured in endothelial basal media (EBM)-2 media and supplemented with a bullet kit which contains various growth factors (ascorbic acid, bovine brain extract, fetal bovine serum [FBS], insulin-like growth factor [IGF], human epidermal growth factor [hEGF], human fibroblast growth factor [hFGF], vascular endothelial growth factor [VEGF], hydrocortisone, heparin), antibiotic (gentamicin), and anti-fungal (amphotericin-B) (Lonza). Colon epithelial normal cells, CCD-841 (American Type Culture Collection, Manassas, VA, USA) were cultured in Roswell Park Memorial Institute (RPMI) 1640 media and supplemented with 10\% FBS; and $1 \%$ penicillin/streptomycin (both from ScienCell, Carlsbad, $\mathrm{CA}$, USA). Both cell lines were maintained at $37^{\circ} \mathrm{C}$ and $5 \%$ $\mathrm{CO}_{2}$ in a humidified incubator.
A

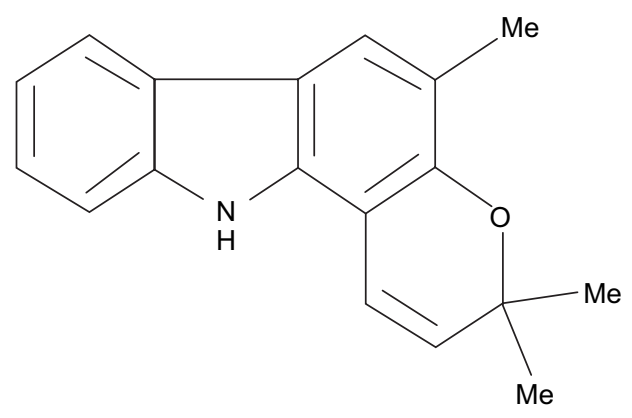

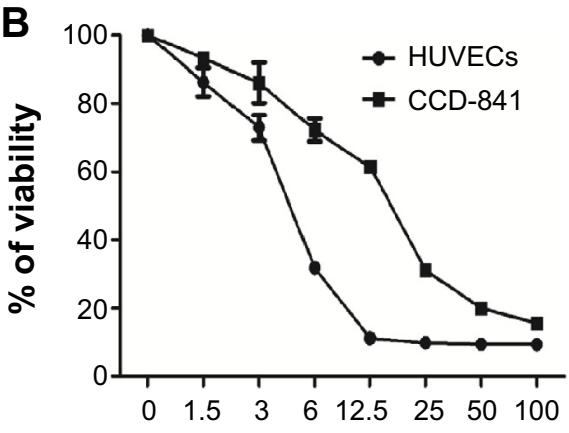

Concentration $(\mu \mathrm{g} / \mathrm{mL})$

Figure I Selective cytotoxicity of girinimbine on endothelial cells.

Notes: (A) Structure of girinimbine (3,3,5-trimethyl-I IH-pyrano[3,2-a]carbazole). (B) Dose-dependent cytotoxic effect of girinimbine on HUVECs and CCD-84I. Abbreviation: HUVECs, human umbilical vein endothelial cells. 


\section{Cell viability assay}

MTT assay determines the percentage of growth inhibition. It is a colorimetric assay in which yellow water-soluble MTT dye is turned into an insoluble purple color in viable cells by the mitochondrial enzyme succinate dehydrogenase. The effect of girinimbine on the inhibition of proliferation on HUVECs and CCD-841 cell lines were tested by using the MTT assay according to the described protocols. ${ }^{26}$

\section{Scratch-wound healing assay}

The wound healing assay was performed as described previously. ${ }^{27}$ HUVECs with a density of $2 \times 10^{5}$ were seeded in 6 well plates coated with $1 \%$ gelatin, and grown in EBM-2 media containing all supplements with $10 \%$ FBS. After 24 hours, confluent monolayers were gently scratched with a sterile $200 \mu \mathrm{L}$ tip to create a uniform wound area. After scratching, cells were incubated in fresh media with 2.5, 5 , and $10 \mu \mathrm{g} / \mathrm{mL}$ of girinimbine. Cell movement and migration into the wound area were examined after 6,12 , and 24 hours by phase contrast microscopy using a $10 \times$ objective. The result was quantified using the WimScratch Image analyzer software (Wimasis GmbH, Munich, Germany).

\section{Capillary tube formation assay}

The effect of girinimbine on HUVECs' morphogenesis was assessed by using in vitro capillary tube formation assay on basement membrane extract (BME; Trevigen, Gaithersburg, MD, USA). In brief, cells with a density of $2 \times 10^{4}$ cells/well were seeded on 96 -well plates which were pre-coated with BME and treated with girinimbine at concentrations of $2.5,5$, and $10 \mu \mathrm{g} / \mathrm{mL}$, respectively. VEGF at $5 \mathrm{ng} / \mathrm{mL}$ and sulforaphane at $5 \mu \mathrm{M}$ were used as negative and positive controls, respectively. After 24 hours' incubation, the media was removed and cells were washed, fixed, and stained with $2 \mu \mathrm{M}$ calcein AM solution. Cells were visualized under fluorescence microscopy (Olympus BX61; Olympus Corporation, Tokyo, Japan) and WimTube Image analyzer software (Wimasis) was used for data analysis.

\section{Invasion assay}

Cell invasion assay is another key assessment of angiogenesis. The effect of girinimbine on HUVECs' invasion was performed using an invasion chamber with 8 micron polyethylene terephthalate membrane and culture chamber and assay chamber (Trevigen). Briefly, the top invasion chamber was coated with coating buffer, $0.1 \times$ and $1 \times \mathrm{BME}$ coating solution and incubated overnight. HUVECs with a density of $2 \times 10^{4}$ cells/ well were added to the top chamber with different concentrations of girinimbine $(2.5,5,10 \mu \mathrm{g} / \mathrm{mL})$. Sulforaphane at $5 \mu \mathrm{M}$ and VEGF at $5 \mathrm{ng} / \mathrm{mL}$ were used as positive and negative controls, respectively. After a 24 hour incubation, non-invasive cells on the upper surface of the membrane were washed and the invasion chamber was transferred to the assay chamber. Two mM calcein AM in cell dissociation solution was added to the assay chamber and incubated for 1 hour. The invasion chamber was removed and assay chamber was read at $485 \mathrm{~nm}$ excitation, $520 \mathrm{~nm}$ emission. Results were calculated by using a standard curve and converted relative fluorescent unit to cell number and determined invasion percentage.

\section{Human angiogenesis proteome profiler array}

To investigate the signaling pathways by which girinimbine affects angiogenesis, we performed a determination of angiogenesis-related protein expression using the Proteome Profiler Array (RayBio Human Apoptosis Antibody Array Kit; RayBiotech, Norcross, GA, USA) according to the manufacturer's instructions. In brief, HUVECs were treated with girinimbine, after which $200 \mu \mathrm{g}$ of extracted proteins from each sample was incubated with the human angiogenesis array overnight. The fluorescence signals were visualized through the Agilent High Resolution Microarray Scanner (C-Scanner; Agilent Technologies, Santa Clara, CA, USA). Row signal data were extracted from the TIFF image with GenePixPro 6.1 microarray and analysis software (Molecular Devices LLC, CA, USA) and analyzed using Q-Analyzer (Ray Biotech, Inc, GA, USA).

\section{In vivo zebrafish assay}

Adult zebrafish were maintained at $28^{\circ} \mathrm{C}$ in a recirculating aquaculture system with 14/10 hour day/night light cycle. Embryos were generated by natural pair-wise mating of adult fish. Breeding boxes were placed into the fish tank overnight. Embryos were collected in the morning and transferred into petri dishes containing system water $(0.2 \mathrm{~g} / \mathrm{L}$ ocean salt in distilled water) and subsequently maintained at $28.5^{\circ} \mathrm{C}$. Healthy fertilized embryos at 20 hours post fertilization (hpf) (21 somite stage) were dechorionated manually prior to incubation in system water containing girinimbine $(20 \mu \mathrm{g} / \mathrm{mL})$. DMSO $(1 \%)$ and SU5416 $(0.25 \mu \mathrm{g} / \mathrm{mL})$ were used as negative and positive controls respectively. After 24 hours of treatment, embryos were returned to normal system water. Embryos were visually observed and monitored daily up to $72 \mathrm{hpf}$ for viability, gross morphological defects, and blood circulation under a stereomicroscope (Olympus SZX10, Olympus Corporation). At $72 \mathrm{hpf}$ embryos were euthanized and fixed in 4\% paraformaldehyde at $4^{\circ} \mathrm{C}$ overnight. In situ endogenous alkaline phosphatase staining was performed to visualize ISVs. ${ }^{28}$ 


\section{Statistical analysis}

Assays were assessed in three independent experiments. Statistical significance was analyzed by using one-way analysis of variance (ANOVA) tests or unpaired Student's $t$-test using Graphpad Prism version 6.0 (Graphpad Software, Inc., La Jolla, CA, USA). Statistical significance is expressed as $* * * P<0.001 ; * * P<0.01 ; * P<0.05$.

\section{Results}

\section{Girinimbine inhibits the proliferation of HUVECS}

Cell viability was analyzed by MTT assay, which measures the cell metabolic activity. In order to rule out the probability of non-selective cytotoxic effects, girinimbine was also tested in parallel on HUVECs and CCD-841 human colon epithelial cells. We performed the treatments with seven concentrations of girinimbine ranging between $1.5-100 \mu \mathrm{g} / \mathrm{mL}$ for 24 hours. As shown in Figure 1B, girinimbine inhibited the proliferation of HUVECs in a dose-dependent manner with an $\mathrm{IC}_{50}$ value of $5 \pm 0.57 \mu \mathrm{g} / \mathrm{mL}$ whilst the anti-proliferative effect on the CCD-841 cells was minimal, with an $\mathrm{IC}_{50}$ of $20.32 \pm 0.41 \mu \mathrm{g} / \mathrm{mL}$ (Table 1).

\section{Girinimbine inhibits the migratory ability of HUVECs}

HUVECs were treated with different concentrations of girinimbine for 6,12 , and 24 hours after which we observed that the migration of HUVECs was inhibited by girinimbine treatment (Figure 2A). Additionally, incubating HUVECs in increasing concentrations of girinimbine resulted in a time- and dose-dependent suppression of HUVEC migration. Quantitative determination of the invaded area showed a significant inhibitory effect after 24 hours in $10 \mu \mathrm{g} / \mathrm{mL}$ of girinimbine (Figure 2B).

\section{Girinimbine inhibits morphogenesis of HUVECs}

Treatment by girinimbine causes immense disruption of the capillary tubes network in contrast to untreated controls (Figure 3A). The tubular structure in girinimbine-treated wells was rather incomplete with fewer branch points and shorter tube length. VEGF, an endogenous pro-angiogenic

Table I MTT results of girinimbine on HUVECs and CCD-84 I

\begin{tabular}{ll}
\hline & IC $_{50}$ values $(\mu \mathrm{g} / \mathrm{mL})$ \\
\hline HUVECs & $5.0 \pm 0.57$ \\
CCD-84I & $20.32 \pm 0.4 I$ \\
\hline
\end{tabular}

Abbreviations: HUVECs, human umbilical vein endothelial cells; MTT, MTT assay; $\mathrm{IC}_{50}$, measure of half maximum inhibitory concentration. factor, and sulforaphane, a well-known angiogenic inhibitor were used as negative and positive controls, respectively. VEGF stimulated complete and well-formed networking of capillary tubes while sulforaphane completely inhibited tube formation. Girinimbine at $2.5,5$, and $10 \mu \mathrm{g} / \mathrm{mL}$ significantly reduced percentage of covered area, number of connected tubes, and total tube length compared to untreated controls (Figure 3B). Quantification measurements demonstrated that girinimbine effectively inhibited HUVECs' tube formation in a dose-dependent manner. This observation suggests that girinimbine has an inhibitory effect on angiogenesis.

\section{Girinimbine inhibits endothelial cell invasion}

Girinimbine was shown to induce an anti-invasive effect on HUVECs in a dose-dependent manner (Figure 4). The rate of invasion decreased from thinner barriers (coating buffer and $0.1 \times \mathrm{BME})$ to the thicker barrier $(1 \times \mathrm{BME})$. The highest invasion was observed in untreated controls in full supplemented media (endothelial cell growth medium) and the lowest one, in EBM which demonstrated an important role of growth factors on cell invasion. Girinimbine at concentrations of $2.5,5$, and $10 \mu \mathrm{g} / \mathrm{mL}$ inhibited cell invasion in all three different barriers as well, despite the presence of growth factors.

\section{Effect of girinimbine on markers of angiogenesis}

After girinimbine $(5 \mu \mathrm{g} / \mathrm{mL})$ exposure, HUVECs were lysed and markers of angiogenesis were screened using a protein array. Girinimbine treatment significantly decreased the expression of VEGF and bFGF, two proteins that are important in sustaining angiogenesis (Figures 5A, C-E). In addition, other major proteins involved in angiogenesis (angiopoietin-1 and -2, angiogenin, epithelial-derived neutrophil-activating peptide [ENA]-78, granulocyte macrophage-colony stimulating factor [GM-CSF], interleukin [IL]-1 alpha and beta, IL-6 and 8, monocyte chemotactic protein [MCP] 1, matrix metallopeptidase [MMP]-9, platelet endothelial cell adhesion molecule 1 [PECAM-1], platelet-derived growth factor BB [PDGF-BB], tumor necrosis factor [TNF]-alpha, urokinasetype plasminogen activator receptor [uPAR]) were significantly down-regulated (Figures 5A-F). All these markers are involved in mediating various angiogenesis steps, including cell proliferation, tube formation, invasion, hematopoiesis, vessels' maturation and stabilization. Meanwhile the treatment resulted in upregulation in the levels of expression of anti-angiogenic markers such as endostatin, interleukin 4 (IL-4) and tissue inhibitor of matrix metalloproteinases-1 (TIMP-1) (Figures 5B, F-H). These markers play important 
A

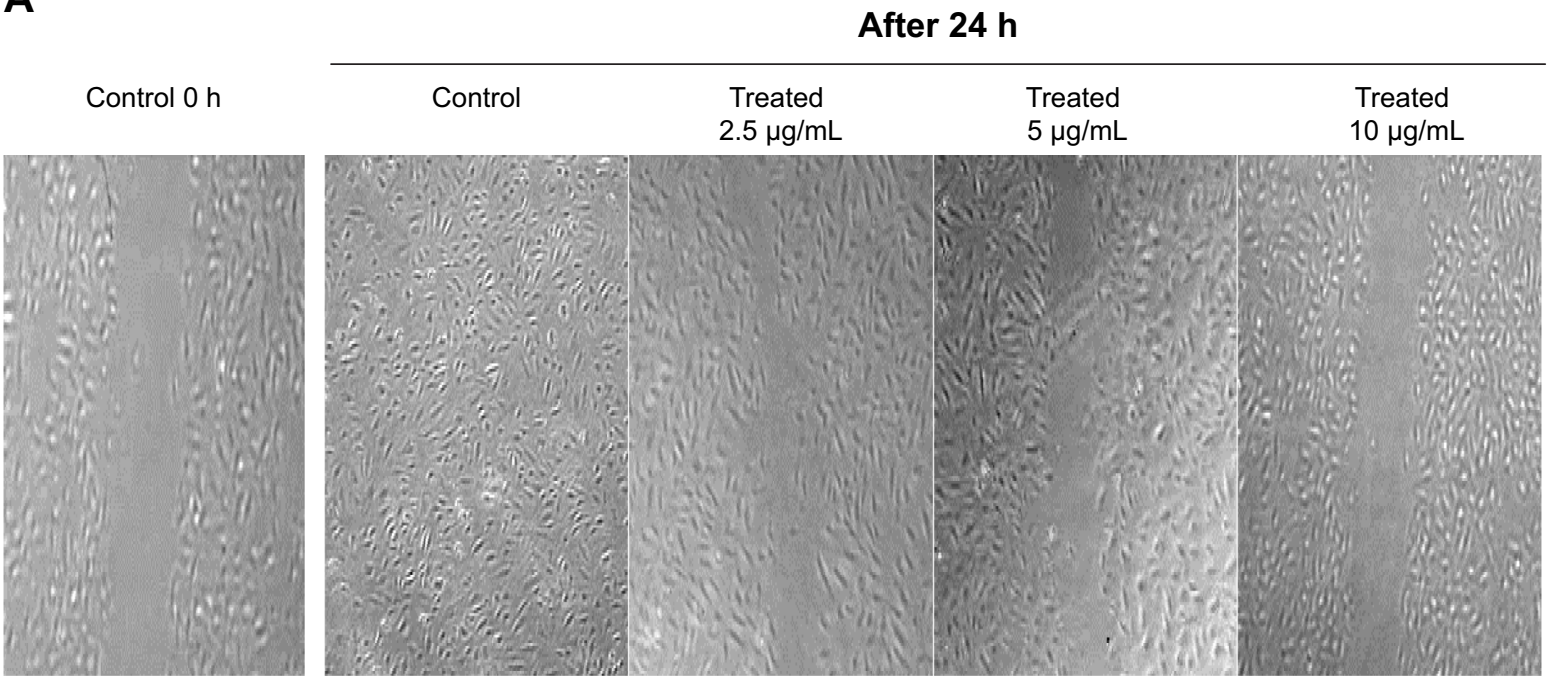

B

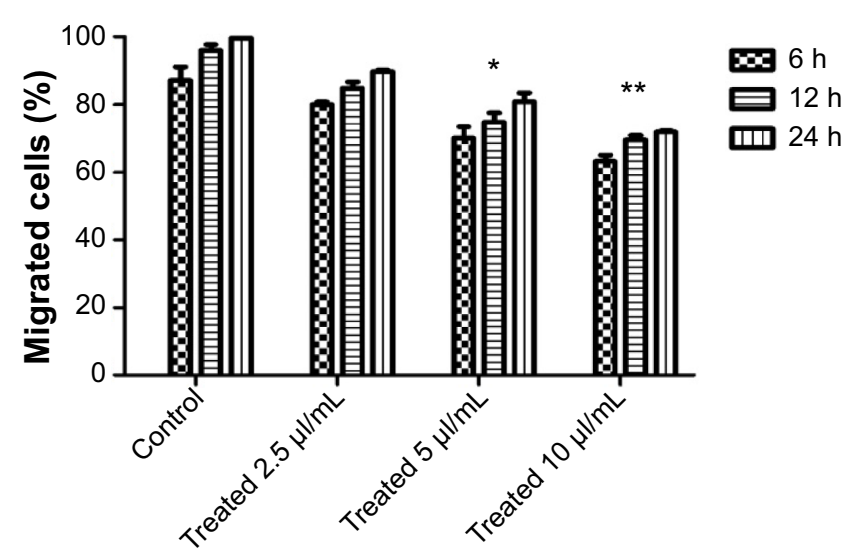

Figure 2 The effect of girinimbine on HUVECs' migratory ability was determined by scratch-wound healing assay.

Notes: (A) Invaded areas in control and girinimbine-treated $(2.5,5,10 \mu \mathrm{g} / \mathrm{mL})$ after $24 \mathrm{~h}$. (B) Quantification of the number of migrated cells after 6 , 12 , and $24 \mathrm{~h}$ exposure to indicated concentrations of girinimbine. Data are shown as percent of cell migration compared to $0 \mathrm{~h}$ control. Statistical significance is expressed as $* * P<0.0 \mathrm{I}, * P<0.05$ versus control.

Abbreviations: HUVECs, human umbilical vein endothelial cells; h, hour(s).

roles in inhibition of endothelial tube formation, activation of anti-tumor agents, prevention of vascular growth, and shrinkage of existing blood vessels.

\section{Girinimbine inhibits ISV formation in zebrafish embryos}

Zebrafish embryos were exposed to girinimbine at $20 \mathrm{hpf}$ (21 somite stage), prior to the development of the ISVs in order to determine the effects of girinimbine on angiogenesis. Following 24 hours exposure embryos were returned to system water for the subsequent 24 hours and development of ISVs was monitored. Pericardial edema was observed in almost all of the surviving embryos that had been treated with either girinimbine or SU5416 (Figures 6A-I). Additionally, hemorrhages were observed over the yolk sac, and tail bending, whole body curvature, and yolk sac enlargement were other marked abnormal phenotypes seen in treated embryos (Figures 6E-F, H-I). These abnormalities are summarized in Figure 6J. The percentages of viable embryos at 48 and 72 hpf are shown in Tables 2 and 3. The percentage of viability at $72 \mathrm{hpf}$ for SU5416-treated embryos was $80 \%$ with $100 \%$ of embryos displaying disruption in blood circulation, while girinimbine-treated embryos had $80 \%$ survival at $72 \mathrm{hpf}$, with $83.3 \%$ of embryos displaying disrupted angiogenesis (Table 3 ). In contrast, the percentage of viable embryos in the vehicle control group ( $1 \% \mathrm{DMSO})$ was $100 \%$ (Table 2), with all embryos displaying normal blood circulation (Table 3). Under light microscopy, the ISVs of vehicle controls were observed to be well formed with robust circulation whereas embryos treated with girinimbine showed 
A

Controls
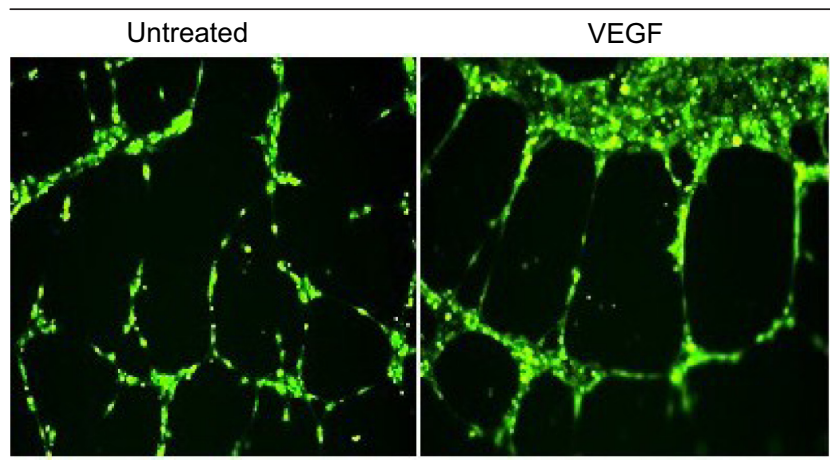

Sulforaphane

Girinimbine treated
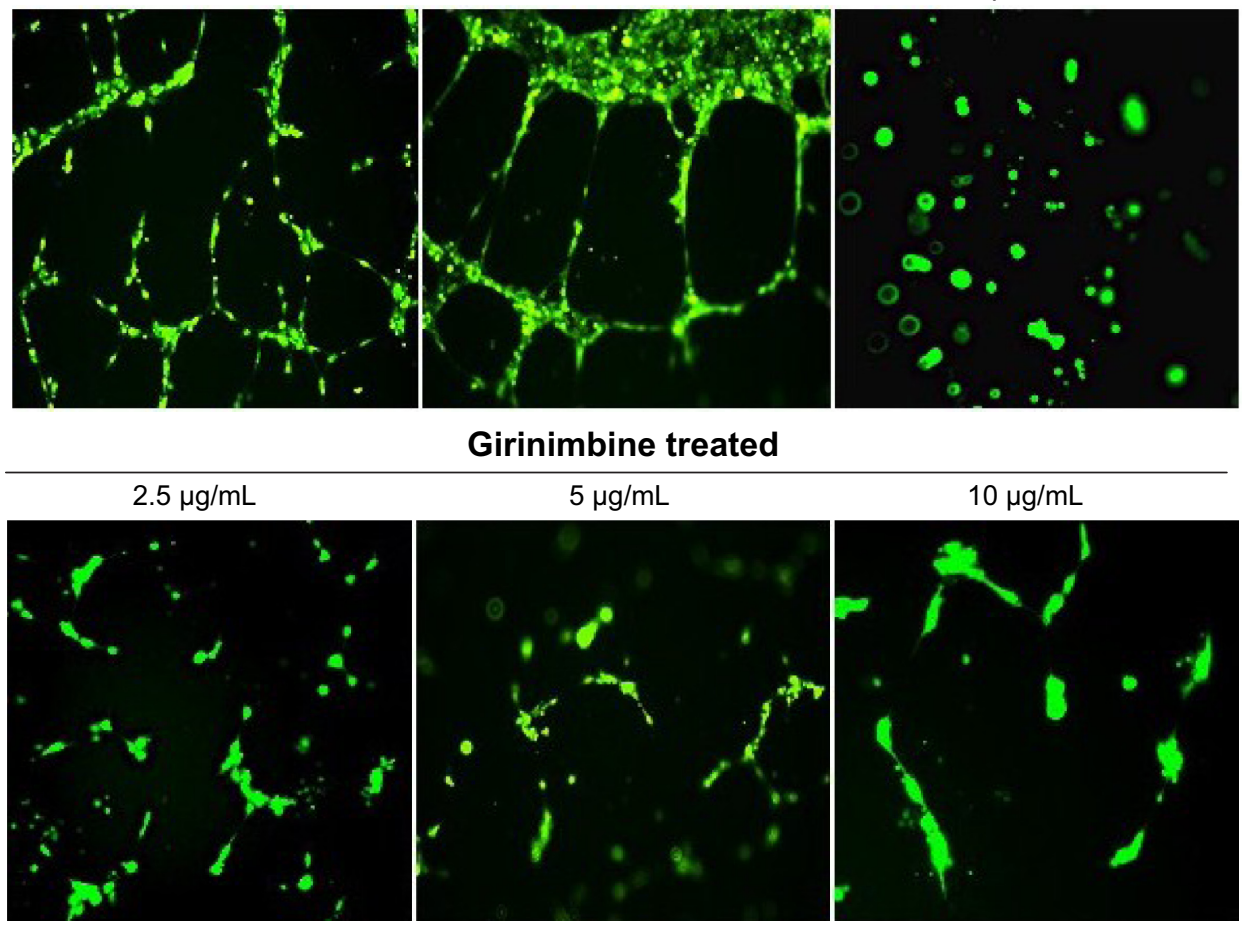

$10 \mu \mathrm{g} / \mathrm{mL}$

B
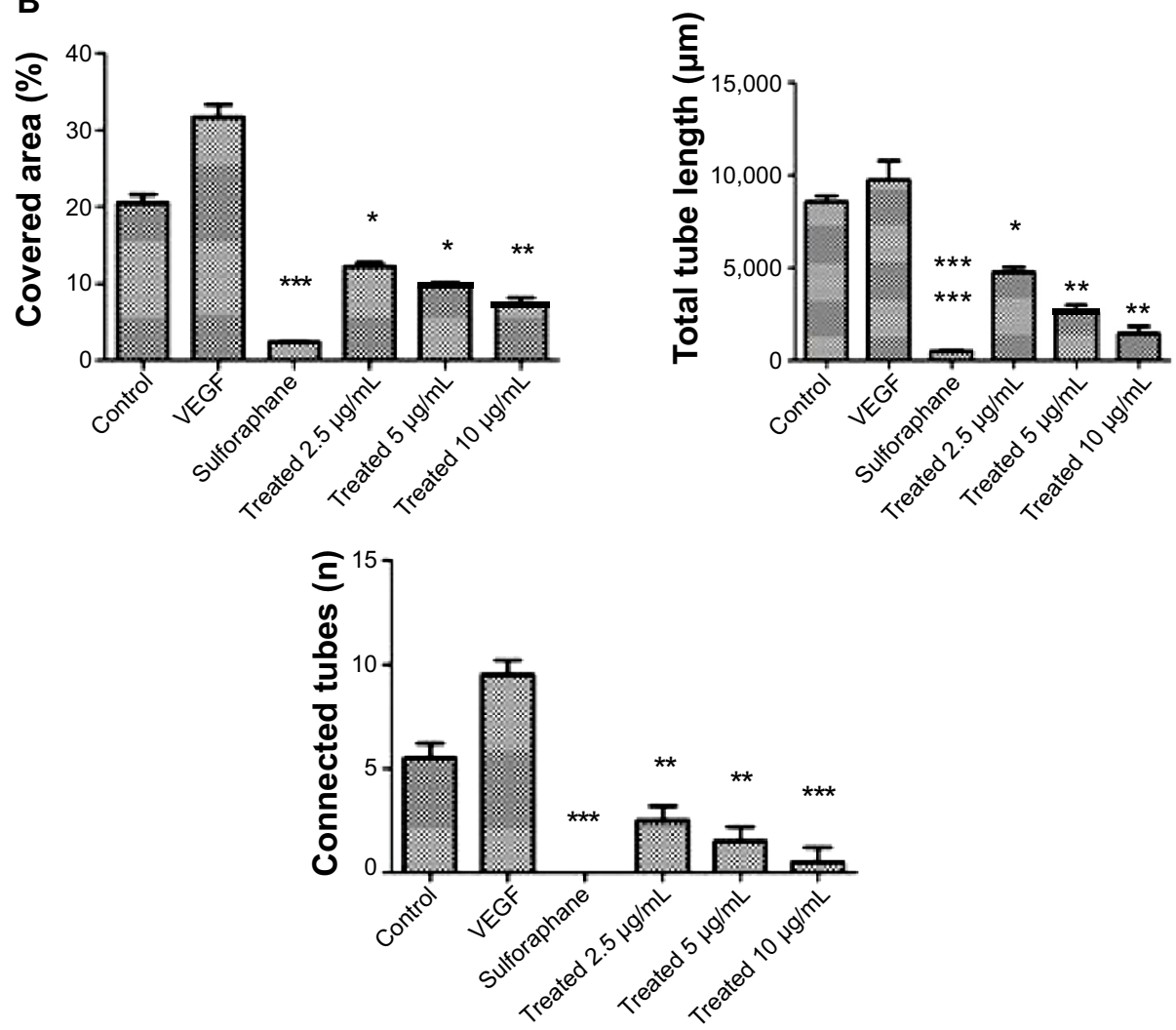

Figure 3 Girinimbine inhibits morphogenesis of endothelial cells.

Notes: (A) Representative images of fluorescent stained HUVECs which were treated with different concentrations of girinimbine in comparison with untreated, positive (VEGF) and negative (sulforaphane) controls. (B) Quantification data for the effect of girinimbine on the tube formation indexes including percentage of covered area, total tube length, and number of connected tubes. Data are shown as means \pm SEM of three independent experiments. Statistical significance is expressed as $* * * P<0.00 \mathrm{I} ; * * P<0.0 \mathrm{I}$; $* P<0.05$ versus untreated control.

Abbreviations: HUVECs, human umbilical vein endothelial cells; SEM, standard error of the mean; VEGF, vascular endothelial growth factor. 


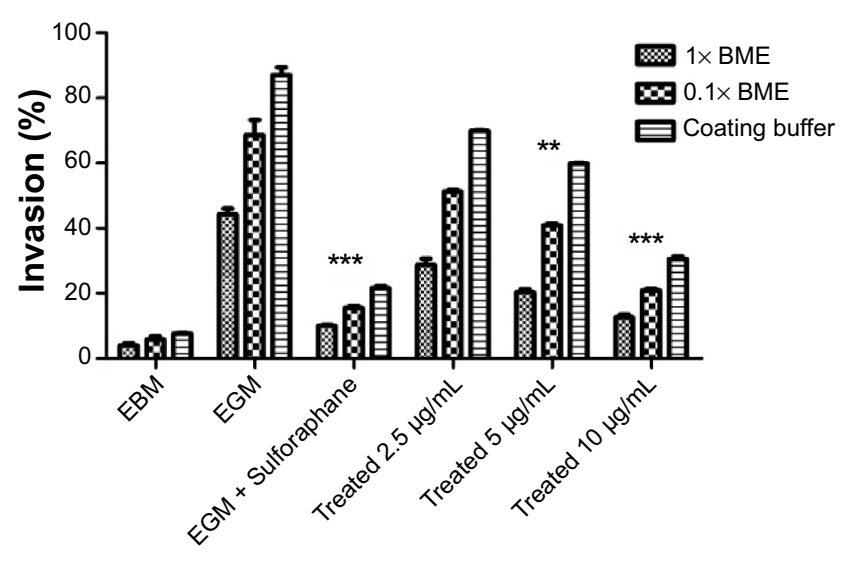

Figure 4 Girinimbine inhibits HUVECs' invasion in dose-dependent manner. Notes: Compared to the control, girinimbine treatment resulted in significant inhibition of HUVECs through coating buffer, $0.1 \times$ and IX BME. Data are given as number of invading cells and are means of two different assays (each carried out in triplicate). Significance is expressed as $* * * P<0.001$ I; $* P<0.01$.

Abbreviations: HUVECs, human umbilical vein endothelial cells; BME, basement membrane extract; EBM, endothelial basal medium; EGM, endothelial growth medium.

incomplete ISV formation, which was also seen in positive control SU5416 embryos. At 72 hpf, endogenous alkaline phosphatase staining was done in situ to visualize the blood vessels in fixed embryos. As seen in Figure 7A, ISVs were well developed in vehicle control embryos at $72 \mathrm{hpf}$, with ISVs arranged in a regular array. Treatment with $20 \mu \mathrm{g} / \mathrm{mL}$ of girinimbine or SU5416 caused disruption in vessel formation (Figure 7B-C). These data suggest that girinimbine inhibits neo-vascularization in zebrafish, therefore inhibiting angiogenesis, which is in agreement with in vitro data.

\section{Discussion}

Herbs have been used in traditional medicine for centuries and are regarded as a valuable source of therapeutic agents. $M$. koenigii is one of the richest sources of carbazole alkaloids among all curry trees and exhibits various biological activities including anti-oxidative, anti-mutagenic, anti-tumor, and anti-inflammatory activities. ${ }^{19} \mathrm{M}$. koenigii has also been shown to have strong anti-tumor activity against leukemia, breast and cervical cancer cell lines. ${ }^{29,30}$ Studies on pure compounds derived from $M$. koenigii are limited. Girinimbine is a carbazole alkaloid extracted from the root and stem bark of M. koenigii, and has been found to have anti-cancer activities against various human cancer cell lines. ${ }^{17,18}$

Angiogenesis is a highly regulated process involving a fine balance between pro- and anti-angiogenic factors. Increasing evidence suggests that imbalance between pro-angiogenic factors, which promote angiogenesis (VEGF, bFGF, MMPs, MCP-1, angiogenin-1, -2) and anti-angiogenic factors which inhibit the growth of new blood vessels (angiostatin, endostatin, IL-4) occurs in diseases with impaired angiogenesis.
Over-expression of pro-angiogenic factors leads to formation of new vasculature that is structurally abnormal at microscopic and macroscopic levels. These abnormalities are exacerbated as a tumor continues to grow. ${ }^{31,32}$

Anti-angiogenic therapy could be a promising strategy for anti-cancer therapeutics. ${ }^{33}$ In this study, we demonstrated the anti-angiogenic potential of girinimbine by its effects on various angiogenic functions of HUVECs, the commonly used endothelial cells for in vitro angiogenesis assays. MTT assays established that girinimbine inhibited the proliferation of HUVECs in a dose-dependent manner and was noteworthy for its non-cytotoxicity at these doses. Moreover, normal colon epithelial cells (CCD-841) were shown to be resistant to girinimbine at the same dose, suggesting there is selective inhibitory function by girinimbine against endothelial cells.

Girinimbine was also found to significantly inhibit the migration, invasion, and tube formation of HUVECs. Endothelial cell migration is one of the key steps in angiogenesis, highlighting the ability to invade surrounding spaces. The results obtained from the wound healing assay clearly showed that girinimbine was able to inhibit endothelial cell migration at the concentrations used. This result was confirmed in the protein array analysis, whereby there was downregulation of GM-CSF, which plays a critical role in activation of endothelial cell migration and proliferation. ${ }^{34}$

Capillary tube formation involves attachment, matrix remodeling and organization of endothelial cells in a $3 \mathrm{D}$ network, and is another requirement for angiogenic progression. HUVECs plated on BME, once stimulated by VEGF, secrete proteases to invade the gel and align themselves to form cords. ${ }^{35,36}$ Using a similar approach, we showed that girinimbine in the presence of VEGF could disrupt tube formation, and the minimal inhibitory concentration for disruption was $2.5 \mu \mathrm{g} / \mathrm{mL}$ (Figure 4). Interestingly, results from the protein array showed that the expressions of proteins regulating vascular tube formation, such as IL-1 alpha, IL-6, IL-8, and MCP-1 were significantly decreased, which served to confirm tube formation inhibition by girinimbine. ${ }^{37-40}$

Cell invasion was also inhibited by girinimbine. Despite the presence of growth factors and different concentrations of barriers (coating buffer, $0.1 \%$ and $1 \%$ BME) girinimbine was found to reduce the total number of cells migrating through the gels (Figure 4). The inhibitory effect was likely to have been achieved through downregulation of key invasion proteins including MMP-9, uPAR, and angiopoietin-1 which play critical roles in degradation of basement membranes and stromal extracellular matrix 


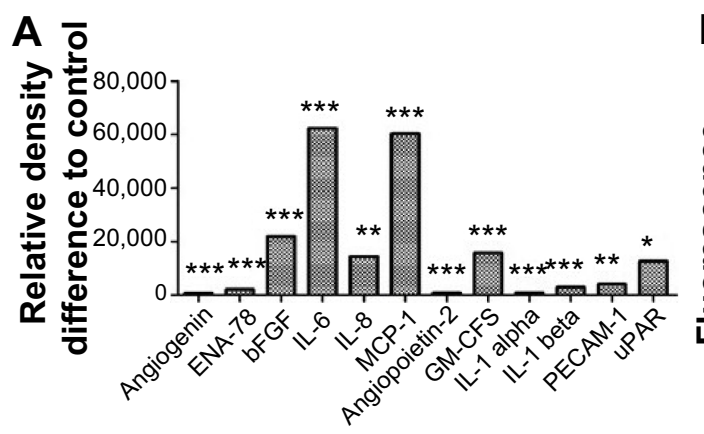

\section{B}
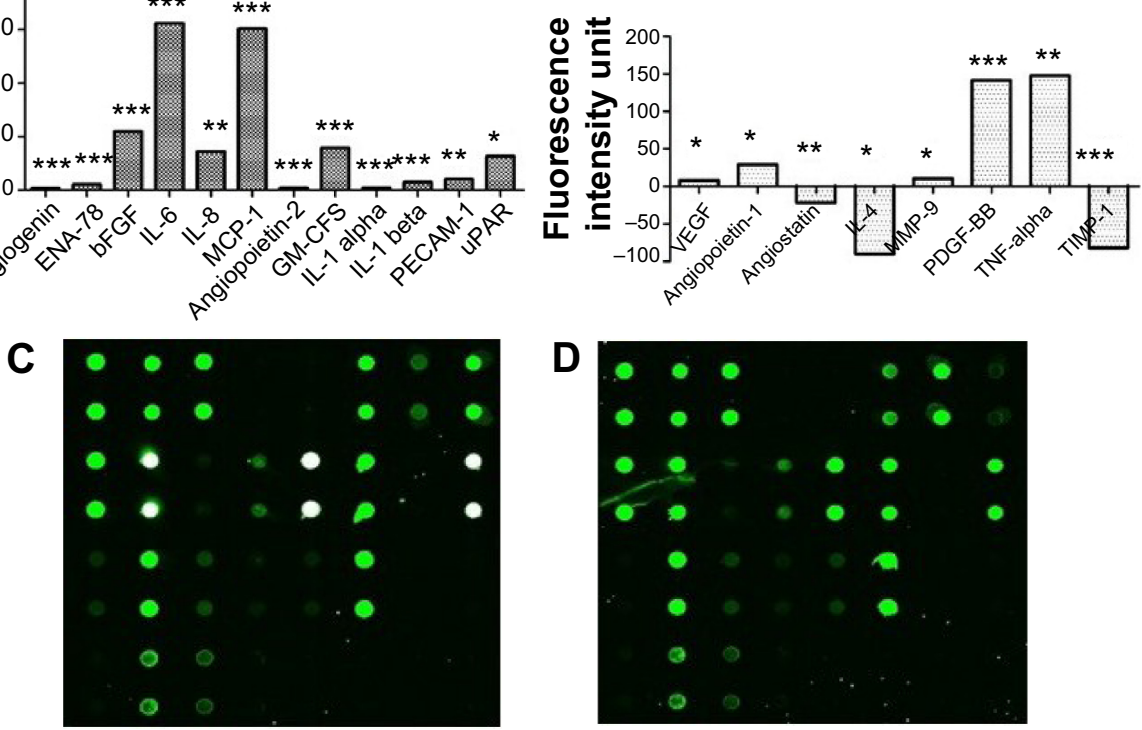

$\mathbf{E}$

\begin{tabular}{|c|c|c|c|c|c|c|c|}
\hline POS-1 & POS-2 & POS-3 & NEG & NEG & Angiogenin & EGF & ENA-78 \\
\hline POS-1 & POS-2 & POS-3 & NEG & NEG & Angiogenin & EGF & ENA-78 \\
\hline b FGF & GRO & IFN-gamma & IGF-I & IL-6 & IL-8 & Leptin & MCP-1 \\
\hline b FGF & GRO & IFN-gamma & IGF-I & IL-6 & IL-8 & Leptin & MCP-1 \\
\hline PDGF-BB & PIGF & RANTES & TGF-beta 1 & TIMP-1 & TIMP-2 & Thrombopoietin & VEGF \\
\hline PDGF-BB & PIGF & RANTES & TGF-beta 1 & TIMP-1 & TIMP-2 & Thrombopoietin & VEGF \\
\hline VEGF-D & IC1 & IC2 & IC3 & NEG & NEG & NEG & NEG \\
\hline VEGF-D & IC1 & IC2 & IC3 & NEG & NEG & NEG & NEG \\
\hline
\end{tabular}
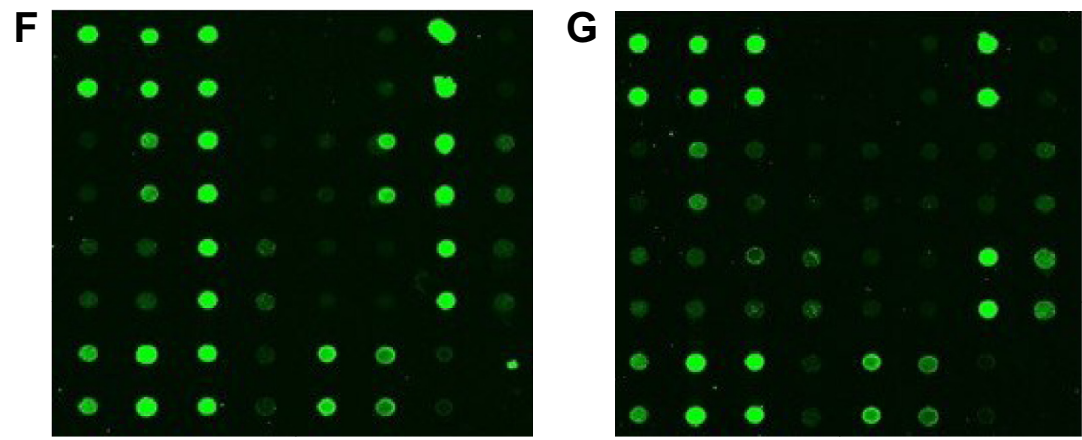

H

\begin{tabular}{|c|c|c|c|c|c|c|c|}
\hline POS-1 & POS-2 & POS-3 & NEG & NEG & Angiopoietin-1 & Angiopoietin-2 & Angiostatin \\
\hline POS-1 & POS-2 & POS-3 & NEG & NEG & Angiopoietin-1 & Angiopoietin-2 & Angiostatin \\
\hline Endostatin & GM-CSF & G-CSF & I-309 & IL-10 & IL-1 alpha & IL-1 beta & IL-2 \\
\hline Endostatin & GM-CSF & G-CSF & I-309 & IL-10 & IL-1 alpha & IL-1 beta & IL-2 \\
\hline IL-4 & I-TAC & MCP-3 & MCP-4 & MMP-1 & MMP-9 & Thrombopoietin & Tie-2 \\
\hline IL-4 & I-TAC & MCP-3 & MCP-4 & MMP-1 & MMP-9 & Thrombopoietin & Tie-2 \\
\hline TNF-alpha & UPAR & VEGF R2 & VEGF R3 & IC1 & IC2 & IC3 & NEG \\
\hline TNF-alpha & uPAR & VEGF R2 & VEGF R3 & IC1 & IC2 & IC3 & NEG \\
\hline
\end{tabular}

Figure 5 Effect of girinimbine on angiogenesis markers.

Notes: Cells were lysed and protein arrays were performed. Cells were treated with $5 \mu \mathrm{g} / \mathrm{mL}$ girinimbine for 24 hours and whole cell protein was extracted. Equal amounts of protein $(100 \mu \mathrm{g})$ from each sample were used for the assay. (A, B) Quantitative analysis in the arrays showed differences in the angiogenesis markers. (C) Representative images of the angiogenesis protein array (series I) are shown for the control and (D) treatment. (E) The exact protein name of each dot in the array. (F) Representative images of the angiogenesis protein array (series 2) are shown for the control $(\mathbf{G})$ and treatment. $(\mathbf{H})$ The exact protein name of each dot in the array. Statistical significance is expressed as $* * * P<0.001 ; * * P<0.01 ; * P<0.05$ versus untreated control.

Abbreviations: EGF, epidermal growth factor; ENA, epithelial-derived neutrophil-activating peptide; GM-CSF, granulocyte macrophage-colony stimulating factor; IFN, interferon; IL, interleukin; I-TAC, interferon-inducible T-cell alpha chemoattractant; MCP, monocyte chemoattractant protein; MMP, matrix metallopeptidase; NEG, negative; PDGF-BB, platelet-derived growth factor BB; PECAM-I, platelet endothelial cell adhesion molecule I; PIGF, phosphatidylinositol-glycan biosynthesis class F; POS, positive; TGF, transforming growth factor; TIMP, tissue inhibitor of matrix metalloproteinases; TNF, tumor necrosis factor; uPAR, urokinase-type plasminogen activator receptor; VEGF-D, vascular endothelial growth factor D; VEGF-R2, vascular endothelial growth factor receptor 2; VEGF-R3, vascular endothelial growth factor receptor 3; RANTES, Regulated on Activation, Normal T Cell Expressed and Secreted; G-CSF, granulocyte colony stimulating factor; b FGF, basic fibroblast growth factor; b, basic. 

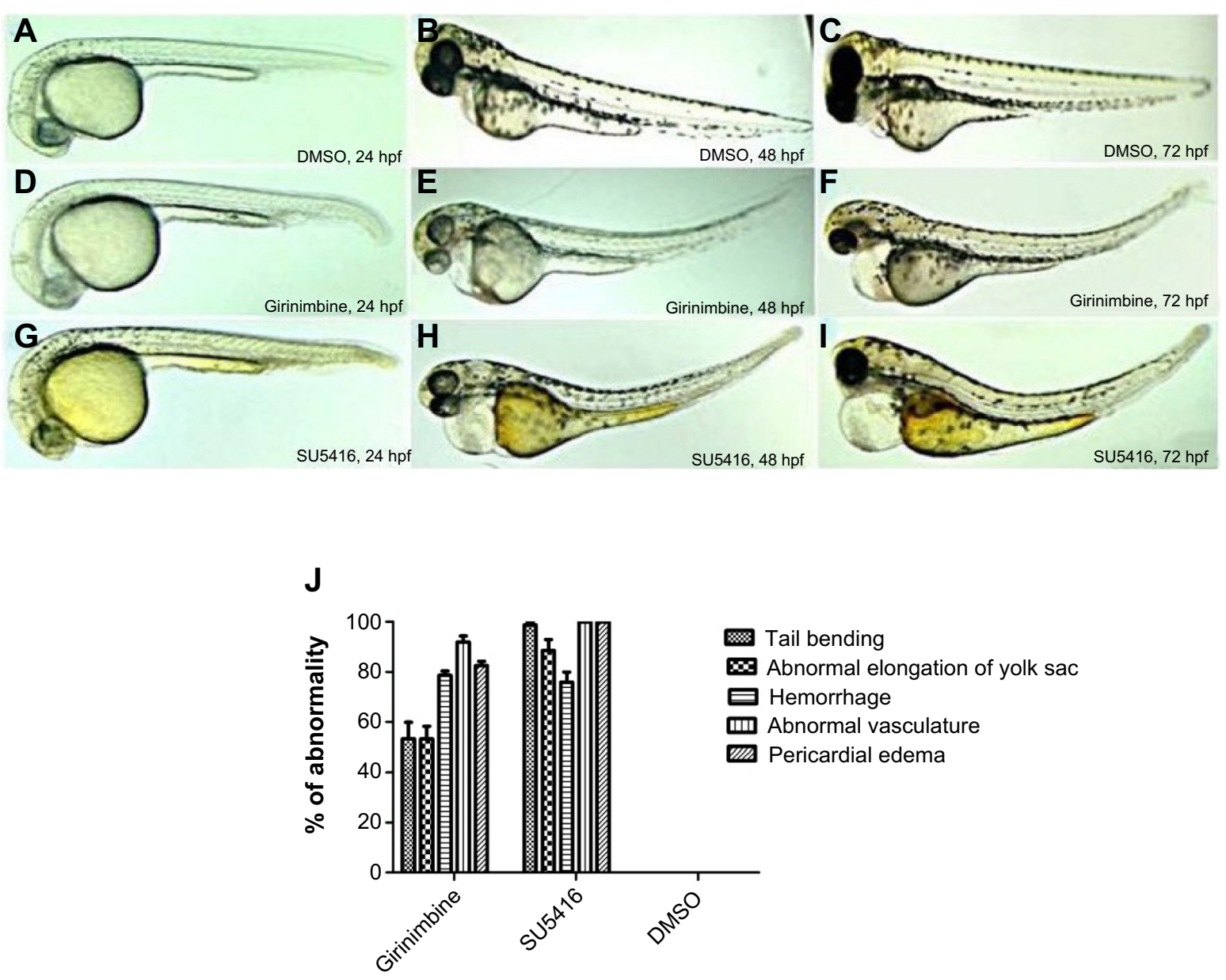

Figure 6 Morphological features of zebrafish embryos.

Notes: (A-C) 24, 48, and 72 hpf vehicle control embryos in I\% DMSO, (D-F) embryos treated with $20 \mu g / \mathrm{mL}$ of girinimbine, (G-I) embryos treated with SU54I6 (positive control). Yolk enlargement, pericardial edema, tail bending, and hemorrhage can clearly be seen in both treated embryos. (J) Phenotype analysis of zebrafish embryos treated with girinimbine, SU54I6 and DMSO at $72 \mathrm{hpf}$.

Abbreviations: hpf, hours post fertilization; DMSO, dimethyl sulfoxide.

for invasion and metastasis of invaded cells (Figures 5A, B). ${ }^{41-43}$ Degradation of extracellular matrix is crucial for invasion and metastasis, and MMPs are pivotal proteinases in this process. ${ }^{44}$

To further investigate the mechanisms of the antiangiogenic properties observed following girinimbine treatment, we performed an angiogenesis-related protein array and found significant differences in the expressions of 20 markers responsible for various angiogenic functions. Two pro-angiogenesis factors, namely VEGF and bFGF, trigger new vessel formation; when these proteins bind to appropriate receptors (VEGFR1, 2, 3 and FGFR1,2) on endothelial cells, a series of signals is activated into the nucleus to produce relay proteins needed for new endothelial cell growth. There is also secretion of proteases followed by degradation of the vessel basement membrane, in order to allow cells to invade the surrounding matrix. Cells proliferate, migrate, and eventually differentiate to form a new, lumen-containing vessel. Therefore inhibition of VEGF and bFGF could lead to successful anti-angiogenic and anti-tumor effects. ${ }^{45}$

Our results indicated that girinimbine did indeed exert its anti-angiogenic effect by downregulation of VEGF and bFGF proteins. Inhibition of VEGF and bFGF expression would have resulted in the inhibition of protein induction for protein groups required for endothelial cell growth and proliferation. As seen in Figure 6, girinimbine treatment also resulted in the downregulation of other angiogenic related proteins such as IL-1 beta which is involved in early angiogenesis and activation of endothelial cells to secrete VEGF ${ }^{46}$ Other downregulated markers were angiopoietin-2, TNF-alpha, and PECAM-1. Angiopoietin-2 in conjunction with VEGF promotes neo-vascularization and TNF-alpha mediates endothelial cell proliferation and stimulates VEGF expression. ${ }^{47,48}$ PECAM-1, a multi-functional vascular cell 
Table 2 Percentage of embryo viability following treatment with girinimbine

\begin{tabular}{llll}
\hline Treatment & $\begin{array}{l}\text { Number of } \\
\text { embryos }\end{array}$ & $\begin{array}{l}\text { Number of } \\
\text { fatalities at } \\
\mathbf{4 8} \text { and } \mathbf{7 2} \text { hpf }\end{array}$ & $\begin{array}{l}\text { Percentage } \\
\text { of viability }\end{array}$ \\
\hline $\begin{array}{l}\text { Girinimbine, } 20 \mu \mathrm{g} / \mathrm{mL} \\
\text { SU54I6 (positive control) }\end{array}$ & 30 & $5^{*} ; I^{* *}$ & $83.2 \% * 80 \% * *$ \\
$0.25 \mu \mathrm{g} / \mathrm{mL}$ & $4 * ; 2^{* *}$ & $86.6 \% ; 80 \%$ \\
$\begin{array}{l}\text { DMSO (vehicle control) } \\
\text { l\% }\end{array}$ & 30 & 2 & $93.3 \%$ \\
\hline
\end{tabular}

Notes: *Number of fatalities observed at $48 \mathrm{hpf}$ (after 24 hour treatment). **Number of fatalities observed at $72 \mathrm{hpf}$ ( 24 hour treatment followed by 24 hour recovery in system water).

Abbreviations: DMSO, dimethyl sulfoxide; hpf, hours post fertilization.

adhesion and signaling molecule, is also involved in endothelial tube formation, migration, endothelial cell-cell adhesion, and endothelial cell-matrix adhesion in the formation of new vessels. ${ }^{44}$ Moreover angiogenin and ENA-78 are other downregulated markers which are responsible for cell proliferation and new vessels' formation respectively. ${ }^{49,50}$ PDGFB, which was also inhibited, is secreted at the final step of angiogenesis to attract supporting cells such as pericytes to regulate vessel stability. ${ }^{51}$

The downregulation of these angiogenic markers was concomitant with the upregulation of anti-angiogenic markers including angiostatin which is involved in the inhibition of proangiogenic factors, ${ }^{52}$ IL-4 which modulates neovascularization, ${ }^{53}$ and TIMP- 1 which is a known suppressor of angiogenesis. ${ }^{54}$ Based on this result, we concluded that girinimbine had a direct effect by significantly decreasing the expressions of angiogenic proteins while increasing the expressions of anti-angiogenic markers.

In addition, the anti-angiogenic potential of girinimbine was evidenced in vivo. The use of zebrafish as an in vivo angiogenesis model has gained much attention due to its physiological similarities to mammals. ${ }^{55,56} \mathrm{We}$ were able to show that girinimbine $(20 \mu \mathrm{g} / \mathrm{mL})$ effectively inhibited angiogenesis in zebrafish embryos following 24 hour exposure (Figure 7B). Exposure to higher concentrations of

Table 3 Inhibition of angiogenesis in zebrafish embryos

\begin{tabular}{lllll}
\hline Treatment & \multicolumn{2}{l}{$\begin{array}{l}\text { Number of embryos } \\
\text { with inhibited vessels }\end{array}$} & $\begin{array}{l}\text { Embryos with } \\
\text { inhibited vessels (\%) }\end{array}$ \\
\cline { 2 - 4 } & $*$ & $* *$ & $* * *$ & \\
\hline Girinimbine & 6 & 8 & 6 & $83.3 \%$ \\
SU54I6 & 10 & 5 & 9 & $100 \%$ \\
DMSO & 0 & 0 & 0 & $0 \%$ \\
\hline
\end{tabular}

Notes: *Inhibition of $\geq 4$ ISVs. **Inhibition of $\leq 3$ ISVs. ***Absence of ISVs. Abbreviations: DMSO, dimethyl sulfoxide; ISVs, inter-segmental vessels.
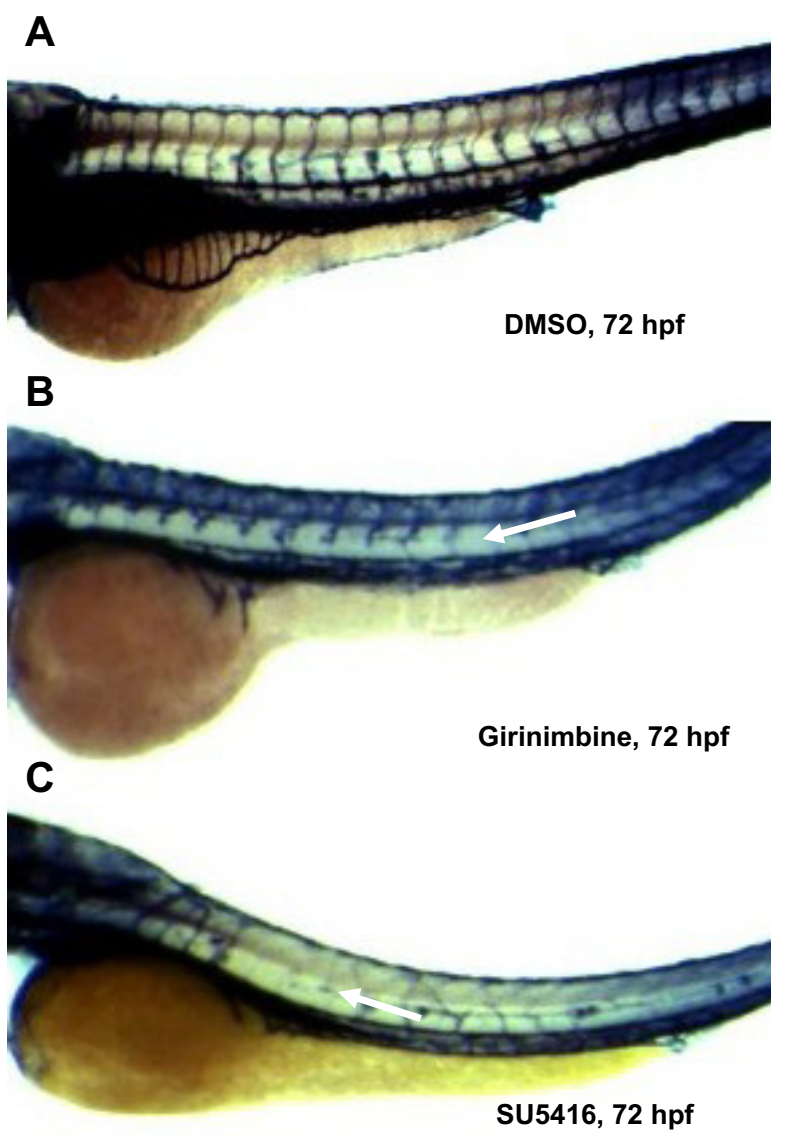

Figure 7 Girinimbine inhibits angiogenesis in the in vivo zebrafish embryo model. Notes: Zebrafish embryos at $24 \mathrm{hpf}$ were dechorionated manually and treated with girinimbine $(20 \mu \mathrm{g} / \mathrm{mL})$, SU54I6 $(0.25 \mu \mathrm{g} / \mathrm{mL})$, and I\% DMSO for 24 hours. Thereafter, the treatment was removed and the embryos were maintained in normal embryo water for another 24 hours and euthanized, then fixed in $4 \%$ paraformaldehyde prior to endogenous alkaline phosphatase activity to visualize the blood vessels. (A) Vehicle control embryo in DMSO. (B) Girinimbine treated embryo. (C) Positive control embryo treated with SU54I6. White arrows denote inhibited ISVs.

Abbreviations: hpf, hours post fertilization; DMSO, dimethyl sulfoxide; ISVs, intersegmental vessels.

girinimbine did not result in toxicity to the embryos, and $20 \mu \mathrm{g} / \mathrm{mL}$ was the minimum concentration of girinimbine to effectively inhibit ISV formation. The anti-angiogenic effect seen with girinimbine treatment however was not as profound as that seen with SU5416 treatment, which produced specific anti-angiogenic effects at $0.25 \mu \mathrm{g} / \mathrm{mL}$ (Tables 2 and 3).

\section{Conclusion}

Our results demonstrated that girinimbine is a potent antiangiogenic compound both in vitro and in vivo, targeting a number of key proteins in angiogenesis. To the best of our knowledge, these results represent the first line of evidence for a novel biological function for girinimbine as an angiogenic inhibitor. Improvement of its current structure for more effective and specific derivatives could also be considered 
for future development of girinimbine as an anti-angiogenic therapeutic agent.

\section{Acknowledgments}

The authors thank Mr Vickneswaran Kanthasamy for assisting in fish husbandry and embryo collection, and the Zebrafish Lab, Animal Experimental Unit, University of Malaya (an AAALAC accredited facility). This work was financially supported by the University of Malaya, Malaysia, through a Postgraduate Research Grant (PG150-2012B) and an UM/ MoHE HIR Grant (H-20001-E00002).

\section{Disclosure}

The authors report no conflicts of interest in this work.

\section{References}

1. Hanahan D, Folkman J. Patterns and emerging mechanisms of the angiogenic switch during tumorigenesis. Cell. 1996;86(3):353-364.

2. Wang $\mathrm{C}$, Tao $\mathrm{W}$, Wang $\mathrm{Y}$, et al. Rosuvastatin, identified from a zebrafish chemical genetic screen for antiangiogenic compounds, suppresses the growth of prostate cancer. Eur Urol. 2010;58(3):418-426.

3. Munoz-Chapuli R, Quesada AR, Medina M. Angiogenesis and signal transduction in endothelial cells. Cell Mol Life Sci. 2004;61(17): 2224-2243.

4. Folkman J. Tumor angiogenesis: therapeutic implications. $N$ Engl $J$ Med. 1971;285(21):1182-1186.

5. Carmeliet P. Blood vessels and nerves: common signals, pathways and diseases. Nature Rev Genet. 2003;4(9):710-720.

6. Vinoth Prabhu V, Chidambaranathan N, Gopal V. A historical review on current medication and therapies for inducing and inhibiting angiogenesis. J Chem Pharm Res. 2011;3(2):526-533.

7. Mackeen M, Ali A, El-Sharkawy S, et al. Antimicrobial and cytotoxic properties of some Malaysian traditional vegetables (ulam). Pharm Biol. 1997;35(3):174-178.

8. Mohan S, Abdelwahab SI, Cheah SC, et al. Apoptosis effect of girinimbine isolated from Murraya koenigii on lung cancer cells in vitro. Evid Based Complement Alternat Med. 2013;2013:689865.

9. Handral HK, Pandith A, Shruthi S. A review on Murraya koenigii: multipotential medicinal plant. Asian J Pharm Clin Res. 2012;5(Suppl 4) $5-14$.

10. Kesari AN, Gupta RK, Watal G. Hypoglycemic effects of Murraya koenigii on normal and alloxan-diabetic rabbits. JEthnopharmacol. 2005; 97(2):247-251.

11. Itoigawa $M$, Kashiwada $Y$, Ito $C$, et al. Antitumor Agents. 203. Carbazole Alkaloid Murrayaquinone A and Related Synthetic Carbazolequinones as Cytotoxic Agents 1. J Nat Prod. 2000;63(7):893-897.

12. Asche C, Demeunynck M. Antitumor carbazoles. Anticancer Agents Med Chem. 2007;7(2):247-267.

13. Ramsewak RS, Nair MG, Strasburg GM, DeWitt DL, Nitiss JL. Biologically active carbazole alkaloids from Murraya koenigii. J Agric Food Chem. 1999;47(2):444-447.

14. Adebajo AC, Olayiwola G, Eugen Verspohl J, et al. Evaluation of the ethnomedical claims of Murraya koenigii. Pharm Biol. 2005;42(8): 610-620.

15. Cui CB, Yan SY, Cai B, Yao XS. Carbazole alkaloids as new cell cycle inhibitor and apoptosis inducers from Clausena dunniana Levl.J Asian Nat Prod Res. 2002;4(4):233-241

16. Knölker HJ. Occurrence, biological activity, and convergent organometallic synthesis of carbazole alkaloids. In: Mulzer J, editor. Natural Products Synthesis II. Springer Berlin Heidelberg; 2005: 115-148.
17. Wang $\mathrm{Sl}$, Cai B, Cui CB, et al. Induction of apoptosis by girinimbine in K562 cell. Chin Tradit Herb Drugs. 2007;38(11):1677.

18. Syam S, Abdul AB, Sukari MA, et al. The growth suppressing effects of girinimbine on HepG2 involve induction of apoptosis and cell cycle arrest. Molecules. 2011;16(8):7155-7170.

19. Ko FN, Lee YS, Wu TS, Teng CM. Inhibition of cyclooxygenase activity and increase in platelet cyclic AMP by girinimbine, isolated from Murraya euchrestifolia. Biochem Pharmacol. 1994;48(2):353-360.

20. Adebajo A, Ayoola O, Iwalewa EO, et al. Anti-trichomonal, biochemical and toxicological activities of methanolic extract and some carbazole alkaloids isolated from the leaves of Murraya koenigii growing in Nigeria. Phytomedicine. 2006;13(4):246-254.

21. Thevissen K, Marchand A, Chaltin P, Meert EM, Cammue BP. Antifungal carbazoles. Curr Med Chem. 2009;16(17):2205-2211.

22. Wang SI, Cai B, Cui CB, Yan SY, Wu CF. Study on induction of apoptosis by girinimbine in HCT-15 cell in vitro. Chin J Pharm Anal. 2008;28(2):176-181.

23. Rubinstein AL. Zebrafish: from disease modeling to drug discovery. Curr Opin Drug Discov Devel. 2003;6(2):218-223.

24. Isogai $\mathrm{S}$, Horiguchi $\mathrm{M}$, Weinstein BM. The vascular anatomy of the developing zebrafish: an atlas of embryonic and early larval development. Dev Biol. 2001;230(2):278-301.

25. Bakar A, Haslizawati N, Sukari MA, et al. Chemical constituents from stem barks and roots of Murraya koenigii (Rutaceae). Malaysian Journal of Analytical Sciences. 2007;11(1):173-176.

26. Alley MC, Scudiero DA, Monks A, et al. Feasibility of drug screening with panels of human tumor cell lines using a microculture tetrazolium assay. Cancer Res. 1988;48(3):589-601.

27. Hu J, Ye H, Fu A, et al. Deguelin - an inhibitor to tumor lymphangiogenesis and lymphatic metastasis by downregulation of vascular endothelial cell growth factor-D in lung tumor model. Int J Cancer. 2010;127(10): 2455-2466.

28. Lai SL, Cheah SC, Wong PF, Noor SM, Mustafa MR. In vitro and in vivo anti-angiogenic activities of Panduratin A. Plos One. 2012; 7(5):e38103.

29. Ito C, Itoigawa M, Nakao K, et al. Induction of apoptosis by carbazole alkaloids isolated from Murraya koenigii. Phytomedicine. 2006; 13(5):359-365.

30. Nagappan T, Ramasamy P, Wahid ME, Segaran TC, Vairappan CS Biological activity of carbazole alkaloids and essential oil of Murraya koenigii against antibiotic resistant microbes and cancer cell lines. Molecules. 2011;16(11):9651-9664.

31. Hampl M, Tanaka T, Albert PS, Lee J, Ferrari N, Fine HA. Therapeutic effects of viral vector-mediated antiangiogenic gene transfer in malignant ascites. Hum Gene Ther. 2001;12(14):1713-1729.

32. Westermarck J, Kähäri VM. Regulation of matrix metalloproteinase expression in tumor invasion. FASEB J. 1999;13(8):781-792.

33. Carmeliet P, Jain RK. Angiogenesis in cancer and other diseases. Nature. 2000;407(6801):249-257.

34. Valdembri D, Serini G, Vacca A, Ribatti D, Bussolino F. In vivo activation of JAK2/STAT-3 pathway during angiogenesis induced by GM-CSF. FASEB J. 2002;16(2):225-227.

35. Lawley TJ, Kubota Y. Induction of morphologic differentiation of endothelial cells in culture. $J$ Invest Dermatol. 1989;93(2 Suppl): 59S-61S.

36. Vucenik I, Passaniti A, Vitolo MI, et al. Anti-angiogenic activity of inositol hexaphosphate (IP6). Carcinogenesis. 2004;25(11):2115-2123.

37. Voronov E, Carmi Y, Apte RN. The role IL-1 in tumor-mediated angiogenesis. Front Physiol. 2014;5:114.

38. Fan Y, Ye J, Shen F, et al. Interleukin-6 stimulates circulating bloodderived endothelial progenitor cell angiogenesis in vitro. J Cereb Blood Flow Metab. 2007;28(1):90-98.

39. Lin Y, Huang R, Chen L, et al. Identification of interleukin-8 as estrogen receptor-regulated factor involved in breast cancer invasion and angiogenesis by protein arrays. Int J Cancer. 2004;109(4):507-515.

40. Yadav A, Saini V, Arora S. MCP-1: chemoattractant with a role beyond immunity: a review. Clin Chim Acta. 2010;411(21):1570-1579. 
41. Kessenbrock K, Plaks V, Werb Z. Matrix metalloproteinases: regulators of the tumor microenvironment. Cell. 2010;141(1):52-67.

42. Binder BR, Mihaly J, Prager GW. UPAR-uPA-PAI-1 interactions and signaling: a vascular biologist's view. Thromb Haemost. 2007;97(3):336-342.

43. Fagiani E, Christofori G. Angiopoietins in angiogenesis. Cancer Lett. 2013;328(1):18-26.

44. Cao G, O'Brien CD, Zhou Z, et al. Involvement of human PECAM-1 in angiogenesis and in vitro endothelial cell migration. Am J Physiol Cell Physiol. 2002;282(5):C1181-C1190.

45. Cross MJ, Claesson-Welsh L. FGF and VEGF function in angiogenesis: signalling pathways, biological responses and therapeutic inhibition. Trends Pharmacol Sci. 2001;22(4):201-207.

46. Carmi Y, Dotan S, Rider P, et al. The role of IL-1 $\beta$ in the early tumor cellinduced angiogenic response. J Immunol. 2013;190(7):3500-3509.

47. Oike Y, Yasunaga K, Suda T. Angiopoietin-related/angiopoietin-like proteins regulate angiogenesis. Int J Hematol. 2004;80(1):21-28.

48. Fajardo LF, Kwan HH, Kowalski J, Prionas SD, Allison AC. Dual role of tumor necrosis factor-alpha in angiogenesis. Am J Pathol. 1992;140(3): $539-544$.

49. Gao X, Xu Z. Mechanisms of action of angiogenin. Acta Biochim Biophys Sin (Shanghai). 2008;40(7):619-624.
50. Arenberg DA, Keane MP, DiGiovine B, et al. Epithelial-neutrophil activating peptide (ENA-78) is an important angiogenic factor in nonsmall cell lung cancer. J Clin Invest. 1998;102(3):465-472.

51. Galvão AM, Ferreira-Dias G, Skarzynski DJ. Cytokines and angiogenesis in the corpus luteum. Mediators Inflamm. 2013;2013:420186.

52. Folkman J. Role of angiogenesis in tumor growth and metastasis. Semin Oncol. 2002;29(6):15-18.

53. Haas CS, Amin MA, Allen BB, et al. Inhibition of angiogenesis by interleukin-4 gene therapy in rat adjuvant-induced arthritis. Arthritis Rheum. 2006;54(8):2402-2414.

54. Ikenaka Y, Yoshiji H, Kuriyama S, et al. Tissue inhibitor of metalloproteinases-1 (TIMP-1) inhibits tumor growth and angiogenesis in the TIMP-1 transgenic mouse model. Int J Cancer. 2003;105(3):340-346.

55. Bakkiyanathan A, Nathan JR, Ravikumar S, et al. Anti-angiogenic effects of theophylline on developing zebrafish (Danio rerio) embryos. Biomed Prev Nutr. 2012;2(3):174-178.

56. Kidd KR, Weinstein BM. Fishing for novel angiogenic therapies. $\mathrm{Br} J$ Pharmacol. 2003;140(4):585-594.
Drug Design, Development and Therapy

\section{Publish your work in this journal}

Drug Design, Development and Therapy is an international, peerreviewed open-access journal that spans the spectrum of drug design and development through to clinical applications. Clinical outcomes, patient safety, and programs for the development and effective, safe, and sustained use of medicines are a feature of the journal, which

\section{Dovepress}

has also been accepted for indexing on PubMed Central. The manuscript management system is completely online and includes a very quick and fair peer-review system, which is all easy to use. Visit http://www.dovepress.com/testimonials.php to read real quotes from published authors.

Submit your manuscript here: http://www.dovepress.com/drug-design-development-and-therapy-journal 